\title{
Perceptions, Competencies and Motivation for Study Choice: Occupational Therapy and Social Work Student Perspectives
}

\author{
*Sylvie Tétreault ${ }^{a}$, Carine Bétrisey ${ }^{a}$, Alida Gulfi ${ }^{b}$ Camille Brisset $^{c}$, Nicolas Kühne ${ }^{a}$, \\ Yvan Leanza ${ }^{d}$ \\ ${ }^{a}$ HES-SO, Haute École de Travail Social et de la Santé, Switzerland; ${ }^{b} H E S-S O$, Haute École de \\ Travail Social Fribourg, Switzerland; ' Université de Bordeaux, France, ${ }^{d}$ Université Laval, Canada
}

\begin{abstract}
Caring for others is one of the most important attributes for individuals who want to be occupational therapists or social workers. Students are not necessarily aware of the challenges and responsibilities of the helping relationship. Deeper insights are needed into these aspects in order to train and prepare students to become competent, work-ready professionals. This study therefore aimed to describe student beliefs about their chosen profession, the competencies they perceived were most important to develop, and their motivators for their choice of profession. In this explorative study, 51 first-year students from occupational therapy (22 students) and social work (29 students) participated in individual semi-structured interviews. The interviews were transcribed and analysed thematically. Although participants had difficulty defining their future profession, they agreed it was all about helping people. A range of competencies was identified, such as establishing interpersonal relationships, sensitivity to difference, communication, flexibility, and teamwork. Differences emerged according to the chosen profession, such as creativity and imagination for occupational therapy students, and administrative skills and the desire to effect change for social work students. Concerning the choice of profession, most participants wanted to help others and engage in human relationships. Diversity and variety of tasks were also attractive elements of both professions. From the beginning of the program, educational institutions should describe more clearly occupational therapy and social work, so that students can develop a realistic vision of their future profession.
\end{abstract}

Keywords: occupational therapy; profession; perception; social work; student

\section{Introduction}

Caring for others is one of the most important characteristics for students who want to be occupational therapists or social workers. This attribute relies on beliefs, values, norms, ethics and morality, which are

*Corresponding Author: Sylvie Tétreault, HES-SO, Haute école de travail social et de la santé, EESP, Lausanne, Chemin des Abeilles 14, 1010 Lausanne, Switzerland

Email: sylvie.tetreault@eesp.ch

Journal URL: https://publications.coventry.ac.uk/index.php/pblh

Tétreault, S., Bétrisey, C., Gulfi, A., Brisset, C., Kühne, N., \& Leanza, Y. (2020). Perceptions, competencies and motivation for study choice: Occupational therapy and social work student perspectives. International Journal of Practice-based Learning in Health and Social Care, 8(1), 15-30. https://doi.org/10.18552/ijpblhsc.v8i1.519

\section{(c) $($ ) $\$$}

BY NC ND (C) 2020 Sylvie Tétreault, Carine Bétrisey, Alida Gulfi, Camille Brisset, Nicolas Kühne, Yvan Leanza. This Open Access article is distributed under the terms of the Creative Commons Attribution Attribution-NonCommercial No Derivatives 4.0 International License (https://creativecommons.org/licenses/by-nc-nd/4.0/ ), which permits unrestricted non-commercial use, distribution, and reproduction in any medium, provided the original work is properly cited and is unaltered. 
said to drive all human behaviours (Egan, 2018). Students' communication competencies are another important aspect to consider (Taylor, 2008), as many professions, including occupational therapy and social work, require the ability to establish a relationship with individuals encountering difficulties in their life and seeking help (Egan, 2018). Moreover, contact with others is central, with all the issues that this relationship entails (discomfort, misunderstanding, prejudice). Students may not be aware of all the challenges and responsibilities entailed in the helping relationship (Egan, 2018). In order to prepare them to become competent and work-ready professionals, it seems essential to investigate their perceptions about occupational therapy and social work, the competencies they need to develop and how they project themselves into their future profession. In fact, if these perceptions are documented, it is possible to gain a more accurate idea of what to include in the curriculum. This study aims to describe student beliefs about their chosen profession, the competencies they perceive are most important to develop, and the motivators for their choice of profession.

\section{Literature review}

While occupational therapy has a history of more than one hundred years, it remains largely unrecognized by society in general. The American Occupational Therapy Association asserts that occupational therapists "help people of all ages participate in the things they want and need to do through the therapeutic use of everyday activities (occupations)" (American Occupational Therapy Association, 2018, para. 2). The Swiss Association of Occupational Therapists and the Committee of Swiss Schools of Occupational Therapy specify that "an occupational therapist has an open, trustful, reliable and empathic attitude towards the patient/client" (2005, p. 9). With these two official definitions in mind, it is relevant to quote research on student perceptions.

Turpin et al. (2012) explored Australian students' perceptions of occupational therapy at the beginning of their educational program. They found that perceptions were similar to those of the general population occupational therapists were viewed as 'helping' professionals. In addition, participants considered rehabilitation as central to the profession (Turpin et al., 2012). Indeed, they defined the goal of occupational therapy activities as enabling people to participate in daily and meaningful activities. Students identified people with injuries or disabilities as groups with which occupational therapy was concerned. They emphasized teamwork, client-centred interventions and professional development as central aspects of occupational therapy (Turpin et al., 2012). When it came to describing occupational therapy to friends, students often used comparisons with other professions such as physiotherapy, nursing or psychology (Turpin et al., 2012). Davis (2008) explored the metaphors used by American occupational therapy students to describe the profession at the beginning of their educational program. Findings showed that occupational therapy was defined as a way of guiding, facilitating, empowering, and enabling people in their lives. Furthermore, notions of client-centred and holistic practice were apparent in their discourse (Davis, 2008).

Other researchers have documented the ideal competencies of a successful occupational therapist. For example, Fleming et al. (1997) found the most important characteristics were: an ability to communicate; dedication to helping people; the capacity to analyze situations logically; and gaining clients' respect. These authors further noted high standards of honesty and integrity, creativity, as well as positive attitudes toward disability. McKenna et al. (2001) found similar results in a follow-up study. Davis (2008) determined that demonstrating caring behaviour, and focusing on clients' needs and problems were, according to the students, essential characteristics. Three studies (Davis, 2008; Fleming et al., 1997; McKenna et al., 2001) have emphasized that individuals with particular characteristics and attitudes tend to choose a profession that values these qualities. It seems therefore that occupational therapy students may already have some of these desired traits when they start their educational program if they are attracted to the profession (McKenna et al., 2001).

Regarding career choice, Byrne (2015) described different sources of influence: internal factors, such as values, interests and personality, and external factors, such as family and friends. Byrne (2015) and Davis (2008) ascertained that the desire to help others (altruism) is a reason for choosing occupational therapy. Moreover, knowing someone who is an allied health professional can guide the career choice, as does the fact that family or friends have received care from such health professionals (Byrne, 2015). Having a personal experience as a patient also influences the decision to become an occupational therapist (Byrne, 2015). As occupational therapy is a relatively unknown profession, students generally discover it through 
personal contacts. The main reasons provided for choosing to study occupational therapy were: to help others; to practise a varied and challenging profession; to work in a healthcare setting; to gain access to many job opportunities; to develop an holistic approach; and to apply one's creativity (Craik \& Zaccaria, 2003).

Social work has existed across the world for many decades. The International Federation of Social Workers defines social work as:

a practice-based profession and an academic discipline that promotes social change and development, social cohesion, and the empowerment and liberation of people. Principles of social justice, human rights, collective responsibility and respect for diversities are central to social work. (International Federation of Social Workers, 2018)

The Swiss Association of Social Workers has recognized competencies for the practice of social work, including the ability to analyze and evaluate situations (individuals, groups, communities, social systems), to lead problem-solving processes in a focused and empathic way in collaboration with clients, to manage external resources, to cooperate with clients, relatives and other professionals, and to reflect on their own professional acting (AvenirSocial, 2014).

In a survey in four countries (Finland, Germany, Slovenia and UK), Hackett et al. (2003) showed that the roles most heavily emphasized by social work students were helping people improve their lives and protecting vulnerable people. Other less important tasks were: providing assessments of needs; advocating on people's behalf; giving advice; and providing financial assistance or therapy (Hackett et al., 2003).

Studies have evoked students' idealistic vision of social work as a source of social change, which may later cause a gap between pre-training perceptions and the reality of the field (Csikai \& Rozensky, 1997; Freund et al., 2017). Csikai and Rozensky's (1997) concept of 'social work idealism' reflects the thoughts and behaviours which value individual and societal change through advocacy to help others meet their basics needs and realize their potential.

Concerning social workers' qualities, students identified empathy as central, followed by openmindedness, a non-judgmental attitude, consideration for differences, and acceptance and respect of others (Hackett et al., 2003). Qualities related to the helping relationship, such as the desire to support people in helping themselves, the ability to advise others, and an interest in individuals, have been identified (Hackett et al., 2003). Furthermore, students suggested listening and communication competencies, self-criticism, and general characteristics such as independence, patience and sensitivity (Hackett et al., 2003).

With regard to choosing social work as a career, Hanson and McCullagh (1995) explained that students generally heard about the profession from their own experiences or from friends or family members who have received such services, or were working in this field. Two main reasons for choosing this profession were being of service to others (for example, helping, contributing to society, effecting social change) and characteristics of the job (such as working conditions, job opportunities) (Hanson \& McCullagh, 1995). Csikai and Rozensky (1997) suggested three types of motives: (1) altruism (e.g. desire to help, possible social change, improving the welfare); (2) professional concerns (e.g. advancement, opportunities); and, (3) exploratory factors (e.g. positive experience with social work, dysfunctional family, encouragement from others). According to Csikai and Rozensky (1997), altruistic reasons are the most common qualities cited by social work students, followed by professional concerns.

Recent studies have reported similar results (Bradley et al, 2012; Hackett et al., 2003). For example, Hackett et al. (2003) observed that the desire both to help people and to support them in overcoming discrimination was cited by the majority of first-year social work students from four European countries (Finland, Germany, Slovenia, and UK). According to these authors, personal experiences were taken into account when social work was chosen as a vocation. Bradley et al. (2012) pinpointed some attributes that most influenced the choice of social work as profession. For example, the authors put forward the desire to be of service to others, dedication to social justice through a commitment for liberty, equality, and dignity of all people, as well as an interest in problem solving with people on an individual basis. 
As for occupational therapy students, Miller (2013) emphasized that people who apply to enter social work tend to have specific values that match the profession. Freund et al. (2017) argued that individuals try to coordinate their self-perceptions, interests, attitudes, and personal ambitions with the characteristics of their career choice. They indicated two types of motivations for choosing the social work profession: personal development and altruism.

The objectives for this study were: (1) to explore student perceptions of their chosen profession (occupational therapy or social work); (2) to identify the most important competencies for students to be an efficient professional; and (3) to describe students' motivations for choosing occupational therapy or social work as a profession.

\section{Method}

\section{Study design}

This study formed a part of an ongoing three-year mixed methods study that aimed to explore how students develop skills to work with people from different cultures, ages, social status, and backgrounds. An exploratory study design was used (Creswell, 2014; Imbert, 2010; Plano Clark et al., 2015) with three phases of data collection planned, one per year. The first and the third phases included individual semistructured interviews and online questionnaires. The second phase consisted only of an individual semistructured interview. The present article corresponds to the first data collection phase.

\section{The educational context}

The study was undertaken in Switzerland where occupational therapy and social work courses are offered in Universities of Applied Sciences and Arts. Courses in class are alternated with fieldwork practice, leading to a bachelors degree. Occupational therapy is a three-year, full-time educational program, and candidates must have either a health profession degree or must complete a preparatory year to acquire basic professional knowledge and competencies. Social work training can be carried out full-time (three years), in parallel with professional working activities (four years), or part-time (five years). It is structured into three main specializations: social workers, psycho-educators, and community-based social workers. For both programs, the number of places available is limited and there is an entrance examination.

\section{Participants}

All first-year, full-time students in the occupational therapy and social work programs from two Universities of Applied Sciences and Art in Western Switzerland were invited to participate voluntarily in the interview of the first data collection $(N=644)$. Two cohorts of first-year students were involved: (a) occupational therapy $(n=52)$ and social work $(n=262)$ students of the academic years 2015-16 were interviewed between June and July 2016; and (b) occupational therapy $(n=53)$ and social work $(n=277)$ students of the academic years 2016-17 were interviewed between October and December 2016.

\section{Data collection method and procedure}

All targeted students $(N=644)$ were invited by email to participate in an individual semi-structured interview. In accordance with the ethical standards of research in Switzerland, agreement from the Universities of Applied Sciences and Art program directors was received before contacting students. Written study consent was obtained from all participants prior to their enrolment.

An interview guide was created following the recommendations of Miles et al. (2014). Open-ended questions (see Appendix 1) were designed to capture: (1) reasons for choosing the occupational therapy or social work educational program; (2) perceptions about their chosen profession; and (3) perceptions about the competencies required. A research assistant (CBé) did all the interviews, in a location and using a communication format (face-to-face, telephone, or Skype) chosen by each participant. Interviews lasted about thirty minutes, according to the amount of information that the person was willing to share (Creswell, 2014). Interviews were audio-recorded with the participant's permission and transcribed verbatim. 


\section{Trustworthiness}

Several measures were implemented to increase trustworthiness (Careau \& Vallée, 2014; Carter et al., 2014; Shenton, 2004). Firstly, credibility was established through the triangulation of sources and analysts. Participants came from two different educational programs (occupational therapy and social work) in two different schools. In addition, two cohorts of first-year students were solicited. Regular discussions occurred between four team members (ST, CBé, NK, AG) at each step of the data analysis process. Secondly, transferability was taken into account by describing the Swiss educational context for occupational therapy and social work. Thirdly, dependability and confirmability were checked in the sense that two team members (AG, $\mathrm{CBr}$ ) reviewed all analyses and findings. Critical decisions and significant events were documented in an audit trail. The same person (CBé) conducted all interviews and kept a logbook. As she was not a teacher in the two educational programs, social desirability bias was reduced.

\section{Data management and analysis}

After a double verification of the accuracy of the audio files with the verbatim transcripts, data were submitted to a deductive thematic analysis approach, based on the three research objectives (Braun \& Clarke, 2006; Creswell, 2014; Miles et al., 2014). Using NVivo® software (Version 11), data were labeled and connected. After familiarization with the verbatim transcripts, open coding was used to identify recurring ideas across interviews and to extract the three major themes: perception of chosen profession, competencies required, and motivations for choice of profession. On this basis, a thematic map was generated (Braun \& Clarke, 2006; Creswell, 2014; Maxwell, 2013), and several categories were identified which related to the three major themes. Following an iterative process, this map was refined, leading to clear definitions for each element. All the analyses were carried out on the basis of the verbatim transcriptions in French. Only quotations presented in this paper were translated into English by the authors.

\section{Findings}

Following the description of the participants, the three themes corresponding to the objectives of the present study will be presented, namely: (1) perceptions of chosen profession; (2) competencies required; and (3) motivations for choice of profession.

\section{Participant characteristics}

The convenience sample consisted of 51 students, including 22 (43\%) in an occupational therapy and 29 $(57 \%)$ in a social work program. Forty-seven women $(92 \%)$ and four men (8\%) participated. The mean age was 23.5 years ( $S D=4.2$ Range: 19 to 42 years). Prior to entering their educational program, 21 respondents $(41 \%)$ had one or more other professional qualification with experience in areas such as business, education, nursing, sciences and arts $(M=1.6, S D=4.3)$.

\section{Perceptions of chosen profession}

About the first theme concerning students' perceptions of their chosen profession, participants' comments were grouped into six different categories: (1) definition of the profession by generalities; (2) client characteristics; (3) workplace; (4) helping people; (5) tools and approach; and (6) interprofessional collaboration. Each of them will be described and illustrated with verbatim excerpts.

\section{Definition of the profession by generalities}

When asked about their future professional tasks, workplaces and clients, participants had difficulty clearly defining their chosen profession. They mainly put forward that any person might require their services. Some of them described their future profession by comparing it to others (physiotherapy or psychology), like this occupational therapy student:

So, well, there are many who ask me if it is... if it's like physio. And then, what I answer them in fact is that it gets closer. We collaborate with physio, but we are rather 
handymen/builders. Finally, in the sense that... what we do is to empower a person by means of using assistive devices (P34).

When defining social work, students often referred to the three specializations of the Swiss programs, namely social workers, psycho-educators, and community-based social workers. A social work student illustrated the situation:

[It] is wide. There are psycho-educators. For me, it's not the same thing as social workers or community-based social workers either. ... I think of them [psycho-educators] more as people who will accompany a population day by day. And then, social workers ... it is more about the administrative side ... [they are] maybe a little more detached ... a little less emotional but [they] can help just as much [as psycho-educators] (P13).

\section{Client characteristics}

Most social work students provided features of potential clients and spoke about disabilities (mental or physical), unemployment or living conditions in poverty. They also expected to work with individuals who are excluded from society because of substance abuse (i.e. drugs, alcohol), sexual orientation, migrant or refugee status. In this sense, a social work student gave some examples of client characteristics:

Well, people with disabilities, people in poverty, children, migrants, sick people too. ... In fact, I know there are people who will ask for help at a given moment, although they are not necessarily in a situation of poverty, nor necessarily ill. ... They are in a particular situation at a specific moment (P13).

Occupational therapy students mainly put forward that any person might require their services, as a participant illustrated:

So, it really concerns all clients, from children to the elderly. ... also ranging from people who are in relatively good physical health to people who are in very poor physical health, and the same for mental health (P03).

\section{Workplace}

Concerning the workplace, occupational therapy students easily named a range of possibilities. For example, this participant explained:

Well, there are plenty of places where occupational therapists can work. It can be in a private practice ... it can be in a hospital or a clinic, whether psychiatric [or physical]. You can see occupational therapists also doing home visits. There may be some in medical specialized centres like ... retirement homes for the elderly. They can intervene in companies ... It can be also in schools, for children in particular (P20).

Social work students acknowledged other places, like prisons, state services, curatorship services, community associations, asylums or street work. A participant described:

I think we find [social workers] everywhere. ... We can already say in state services, in associations, foundations, in homes for the elderly, in all centres and institutes in fact. And apparently there are also quite a few working with people on the street (P13).

\section{Helping people}

Participants from occupational therapy explained the importance of helping people regain functional independence to be able to perform activities. An occupational therapy student detailed her thoughts:

I would say that it is a job in which we try to find solutions and ways of doing things so that people who have difficulty in any field can overcome this difficulty... not necessarily overcome it, but succeed in doing what they want to do... within the possibility of their capabilities... help them find ways of doing things, having new ideas (P29). 


\section{Tools and approach}

All social work students recognized the necessity to support people in difficulty, including those who dropped out of society. They stipulated the importance of defending individual interests and working with people to facilitate social integration. In this regard, a student voiced her opinion:

It's really about providing individual support, whether it's in a group, on a temporary basis or in a sustainable way, to be able to integrate them too, in a society or a community (P13).

Many social work students gave details about how to support the person's autonomy in the intervention process. Sometimes, they communicated empowerment perspectives in social work and how to promote this. Thus, a participant communicated his perception:

I find that the notion of guiding, not necessarily helping, yes, but I find rather guide. In fact, we don't do the work alone. In everything we do, the person, the beneficiary is with us. ... We really have ... to be there to help him to do what it takes to reach his goal in fact (P30).

For example, they may provide clients with resources such as money, housing, and psychological support. Also, they may help them in acquiring specific skills to be more independent or to be able to manage life situations.

Occupational therapy students gave examples of professional assignments, as this participant illustrated:

It can be creative, craft activities. It's a bit like training in activities of everyday life. It can be going to the workplace and changing aspects of the environment in the workplace or at home, a little bit everywhere, providing assistive devices, teaching new techniques, whether activities or transfers (P03).

\section{Interprofessional collaboration}

Both occupational therapy and social work students stressed the need for multidisciplinary teamwork, giving examples of their mutual professional activities: interviews, setting up projects, follow-up, budget management, and psychosocial support. One social work participant spoke about social justice and professional practice constraints:

Social work is the living expression of solidarity in society. I totally agree. ... reality is somewhat... you have to nuance it and there are actually many limits. It concerns the socioeconomic context. It concerns the law, the State that imposes things. ... And we are not alone. We have to work with a lot of actors. We are also integrated into institutions and ... our flexibility is to question (P06).

Another social work student addressed professional burnout:

It is obvious that there are also ups and downs in this profession. You have to be very careful. We know that it's also a job that can be subject to burnout. ... But it's also by learning to know oneself better that perhaps we can identify more quickly signs of that, to know how to listen to oneself (P11).

\section{Competencies required}

The second theme is about the most important competencies required to be an efficient professional. Six categories emerged: (1) interpersonal competency; (2) personal ability; (3) communication competency; (4) creativity; (5) ability to face challenges; and (6) organizational competency. Some categories relate to both social work and occupational therapy, while others are specific to one or other of the two professions. Each category will be described and illustrated with verbatim excerpts. 


\section{Interpersonal competency}

The major competency considered as crucial by all students was interpersonal abilities, such as respect, tolerance, non-judgmentalism, open-mindedness, patience and altruism. An occupational therapy student affirmed:

Yes, so I think we must already love the relationship, be comfortable with people, be interested in people, have some ability to empathize too, finally, be able to listen (P10).

Similarly, a social work student highlighted sensitivity to differences:

... patience, listening and especially tolerance, I would say, because they are also people who are not... who are different from us, not necessarily physically or mentally, but different, even in their way of thinking or speaking or whatever, to express themselves in general (P15).

\section{Personal ability}

Students from both programs underlined the necessity of being authentic, sincere, and respectful of confidentiality. They insisted on the need to maintain a therapeutic distance: being close enough to create a therapeutic alliance and at the same time trying not to be personally affected by a clients' life situation. An occupational therapy student defined this ideal position:

Perhaps an ability to find a reasonable position, that is not being too much in close ties, but not too withdrawn either, to find a correct distance (P22).

\section{Communication competency}

Many participants referred to the importance of communication competencies, such as being comfortable to start a dialogue, discussing sensitive subjects and being a good listener, as this occupational therapy student pointed out:

I would say to listen to the person ... because if we think she should do something and it would be good for her, but we don't hear that it's not important [for her], we can set goals, do everything possible to make it happen, but if she doesn't want to, she doesn't want to. It will not work (P01).

Other professional competencies such as flexibility, adaptability and the ability to work as part of a team were brought up. A social work student noticed:

So I think that a social worker is someone who knows how to adapt according to the places where he works, and who succeeds in doing his job in the same way, and at the same time differently, in different contexts (P16).

\section{Creativity}

Although all the competencies mentioned so far are similar for occupational therapy and social work, some abilities seemed specific to one or the other. For example, only occupational therapy students suggested creativity, imagination, curiosity and problem-solving as core competencies. In this regard, a participant clarified:

I think a bit of a creative side can help too. ... I think that creativity in the sense of finding solutions that we wouldn't have thought about, or methods that may not yet exist, readapt also according to the situation, so create new methods (P09).

\section{Ability to face challenges}

Alternatively, social work students identified factors such as challenging oneself and gaining perspective, acquiring emotional strength, motivation and willingness to make things change. For example, this participant affirmed: 
Social workers should be able to change things when they have to be changed. ... if an unfair decision was made, ... it's his role to make things change with regard to society, the state and political decisions. (P17).

\section{Organisational competency}

A few social work students brought up organizational and administrative competencies as central abilities to acquire. This student noticed:

But also more technical skills, especially if you work in a social service. You have to know the laws. You have to know the social insurance, the rules, because there is a whole range of insurance (P06).

The described skills and knowledge can be learned through training and practice, especially fieldwork.

\section{Motivations for choice of profession}

Participants described different paths that led them to choosing their future profession. This third theme is divided into six categories: (1) personal experience; (2) desire to explore new avenues; (3) relational aspects; (4) sense of usefulness; (5) diversity of the profession; and (6) personal growth and social change.

\section{Personal experience}

Some participants evoked their personal experience as a beneficiary of occupational therapy or social work services, or that of a relative. This social work student illustrated how she came to choose social work:

So, it's a lot due to family stories, especially with my dad ... who is receiving social [services]. So, that interested me a lot. It was after that... that I got really interested in the social field (P02).

Students from the occupational therapy and social work programs put forward the knowledge of a person (family or friend) working in the chosen professional field or similar. Many participants indicated that previous professional experiences, internships or advice from an orientation counsellor made them pick their profession. An occupational therapy student explained his career path:

And then at school, I did an internship at a physio. And I liked it, but I thought it was the same thing all the time and then it was a lot of massage and it was a lot of movement. And I asked him if he knew a job that was a bit more creative .... And then he told me that there was occupational therapy. (P05).

\section{Desire to explore new avenues}

Several occupational therapy and social work students shared their need for a professional reorientation following a failure in other professional fields, like medicine, physiotherapy, dietetics or psychology. For example, an occupational therapy student shared his experience:

So, after my failure in medicine, I still wanted to stay in a field that concerned health. ... I looked at the possible options. For me, being a nurse, medical radiology technician or a physiotherapist were not professions that interested me. Dietetic, kinesiology and occupational therapy remained. (P35).

A few social work participants also explained their choice as a desire to continue their education and attain a higher status.

\section{Relational aspects}

Concerning the elements that attracted them to the chosen profession, the main reasons given by students from both programs were the relational aspects, especially the desire to engage in human relationships. 
They indicated that occupational therapy and social work would allow them to have privileged contacts, to help and support others. One social work student confirmed this:

Because I really like being able to accompany people from day to day, to see development, to be with them every day. ... Yes, to be able to really create a link, to get to know these people, to be able to do the best I can to help them (P11).

In addition, a social work student said that teamwork and sharing with colleagues was important for her.

\section{Sense of usefulness}

Participants wanted to be useful to others, to help and to make a difference. This is how this occupational therapy student explained his interest in his future profession:

Well, I would say that firstly, it is mainly about being useful to others, being of any value. ... I wanted to really have this direct connection [with people] and to feel that what I do every day really brings something to people (P29).

\section{Diversity of the profession}

Another attractive element for the profession was the diversity of tasks or the variety of work, as this occupational therapy student illustrated:

There are many different things you can do. And then, I like it when things move, when there are new challenges. ... But here, the fact of still being able to work with different populations, it is also an aspect which I like in this profession (P33).

The evolution, specializations and different possibilities of the profession were also reported, allowing future career changes within the same profession. Students put emphasis on the necessity of having a job with many challenges and opportunities, because they did not want to fall into routine and boredom.

Other reasons students mentioned were specific to their choice of profession. For example, the manual and concrete aspects of the profession, as well as creativity, imagination and problem-solving attracted occupational therapy students. Moreover, they put emphasis on the person-centred approach, and the mix in occupational therapy between health and social care.

\section{Personal growth and social change}

With regard to social work, some participants put forward the possibility of personal enrichment, as this male social work student said:

I really like that aspect, that we can ... that we evolve, that we can work on ourselves, ... and that has repercussions on others, and vice versa (P22).

It is interesting to note that only one social work student spoke about interest in social change. This young woman explained that her family is a foster family. As two children go to a social centre, she pointed out how her private life and her professional occupation have become linked:

I find it very interesting to be able to see both sides in fact. ... Well, I hear as much the [opinion] of the professional who criticizes the foster family as the foster family who criticizes the professional. ... Actually, these are the two sides that I live, that challenge me, that interest me (P03).

In this sense, she wants to be able to influence change in some situations.

\section{Discussion}

This study explored occupational therapy and social work students' perceptions of their chosen profession. It was hard for most participants to define their own profession because professional fields are 
broad and sometimes complex (Turpin et al., 2012; Freund et al., 2017). Participants named many places of practice, which were similar to those listed on professional websites (American Occupational Therapy Association, 2018; International Federation of Social Workers, 2018). Congruent with previous research, occupational therapy and social work participants identified their clientele as people of all ages presenting with a variety of conditions (Hackett et al., 2003; Turpin et al., 2012).

Students from both educational programs fervently wanted to help people, as shown in other studies (Davis, 2008; Hackett et al., 2003; Turpin et al. 2012). They also stressed interprofessional collaboration, which is considered by many authors to be an efficient way of providing social and health care services (Careau et al.,2014). Occupational therapy students added other elements, like focusing on daily life activities that make sense to people. For social work, participants emphasized the defence of the people's interests and empowerment. Only one participant mentioned the idealistic vision of social work (source of social change) described in the literature (Csikai \& Rozensky, 1997; Freund et al., 2017). However, both of these studies used questionnaires which may have led their participants to report this aspect specifically.

The second goal was to identify the competencies necessary for an occupational therapist or social worker. Most of the competencies were the same for all participants, regardless of their educational program. This was the case for relational abilities (e.g. respect, tolerance, altruism, open-mindedness), which has also been found in other studies (Fleming et al., 1997; Hackett et al., 2003; McKenna et al., 2001). It is interesting to note that positive attitudes to disability did not appear in the present results, unlike other research (Fleming et al., 1997; Hackett et al., 2003; McKenna et al., 2001). In the current study, participants talked more about sensitivity to difference, which could be understood as a similar, but perhaps broader notion.

Communication competencies were frequently highlighted in the interviews, as reported in previous studies (Fleming et al., 1997; Hackett et al., 2003; McKenna et al., 2001). Similarly, flexibility and adaptability were also cited by students from both educational programs. In contrast with other works consulted (Davis, 2008; Fleming et al., 1997; Hackett et al., 2003; McKenna et al., 2001), competencies related to teamwork and the ability to maintain a professional distance from beneficiaries appeared in the students' discourse. This may be related to the fact that the researchers in the aforementioned studies used a questionnaire, instead of semi-structured interviews. This finding supports the usefulness of qualitative methodology as a way of achieving a more accurate understanding of student perceptions.

Students raised other competencies. For instance, occupational therapy students identified creativity, imagination and problem-solving abilities, which are consistent with Fleming et al. (1997) and McKenna et al. (2001). Social work students discussed challenging oneself and acquiring some perspective on the experience, having a desire to make things change, authenticity, and sincerity. While these characteristics were similarly cited by Hackett et al. (2003), participants in the present study named organizational and administrative competencies, which were not indicated by Hackett et al. (2003). This could be due to practice variations within institutions and regional contexts.

The third objective of this study was to describe the students' reasons for choosing occupational therapy or social work as a profession. As in some studies (Byrne, 2015; Craik \& Zaccaria, 2003; Csikai \& Rozensky, 1997; Hanson \& McCullagh, 1995), participants, or someone close to them, had received services, either in occupational therapy or social work. Often they indicated knowing people who work in occupational therapy or social work, or similar fields. In the present results, participants also shared that other professional experiences (including internships) or reorientations had been reasons for choosing their profession; this has not been shown previously in the literature. This finding reveals that students do not always choose to go directly into these professions.

Most authors (Bradley et al, 2012; Byrne, 2015; Craik \& Zaccaria, 2003; Csikai \& Rozensky, 1997; Freund et al., 2017; Hackett et al., 2003; Hanson \& McCullagh, 1995) agree that students who choose occupational therapy or social work educational programs are motivated by the desire to help others (altruism). This was confirmed in the present study. Contrary to previous social work research (Bradley et al, 2012; Csikai \& Rozensky, 1997; Hanson \& McCullagh, 1995) which indicated a motivation for social change or social justice, occupational therapy and social work students in this study put forward their commitment to human relationships and the importance of being useful. For example, specific characteristics of the occupational therapy profession, such as manual, concrete, and creative aspects or 
the person-centred approach, were also found attractive in Craik \& Zaccaria's study (2003). Similarly, social work students highlighted their interest in teamwork and personal enrichment as did Bradley et al. (2012) and Freund et al. (2017). For participants from both programs, diversity and variety in professional tasks were attractive elements for choosing their profession, as well as the possibility for development and specialization. This has been observed in previous studies (Craik \& Zaccaria, 2003; Csikai \& Rozensky, 1997; Hanson \& McCullagh, 1995) which cited elements such as salary or job opportunities which was not the case in the present results.

Exploring students' perceptions of their future profession allows understanding of how professional identity is developed. In fact, professional identity will evolve during the educational program. Courses and internships allow students to modify their perceptions in order to reach a more realistic vision of the occupational therapy and social work professions. As Turpin et al. (2012) reported for occupational therapy, if professionals cannot clearly explain their role and the purpose of their profession, it will not be better understood by the general population and by future students. That is why the content taught in educational programs must be adapted to perceptions held by students. In this way, information conveyed on websites or other means needs to provide clear definitions and descriptions of the occupational therapy and social work professions. In this way, students may be better prepared for their future profession, and will be able to make informed choices without idealizing the profession.

This study has some limitations, which require caution with regard to making any generalizations. First, participants were from two French-speaking Swiss institutions and presented heterogeneous paths (for example, professional experiences, preliminary formation, personal experiences). Some students may have previously worked in a similar field, which may have given them a better idea of the profession and the skills required. A second point to note is social desirability bias. Being interviewed face-to-face could push students to give what they think is 'the correct answer'. However, the researcher who did all the interviews was neither an occupational therapist nor a social worker, which may have reduced this bias. Thirdly, studies that used questionnaires with predetermined answers mentioned the importance of interviews to capture students' perceptions more effectively (Bradley et al, 2012; Byrne, 2015; Turpin et al., 2012). The use of interviews was therefore a strength in terms of providing a more detailed picture of student perceptions, despite the possibility of social desirability bias, which also exists in quantitative methodology (Larson \& Bradshaw, 2017).

\section{Conclusion}

This research gives an overview of students' perceptions about their future profession in health (occupational therapy) and social care (social work). Most participants defined their chosen profession by generalities, giving various examples of clients and workplaces. Helping people was the main factor put forward by participants of both educational programs. Other elements included tools, approaches used, and interprofessional collaboration. Competencies participants considered crucial for becoming a workready professional were interpersonal, personal, and communication abilities. In addition, specific competencies were mentioned, such as creativity for occupational therapy students, and organizational competency and an ability to face challenges for social work students. Motivations for choice of profession included personal experience and a desire to explore new avenues, as well as the relational aspect and sense of usefulness. Other reasons related to the diversity of the profession, personal growth and social change.

The findings point to the importance of accurate information to help students decide on their career choice. Future research might examine teaching methods and tools that can assist potential students to develop a clearer idea about their choice of profession, and to understand the importance of human relationships and knowing themselves. Pedagogic approaches should help students develop links between theory and practice by integrating key elements and using concrete examples of interventions to guide their reflections about professional actions, as well as difficulties potentially encountered.

\section{Acknowledgements}

The authors would like to thank all students who consented to participate at this research. 


\section{Funding}

The authors received a grant to undertake this research by the Swiss National Research Foundation (Tétreault, Gulfi, \& Kühne, 2016-2019).

\section{ORCID}

Sylvie Tétreault https://orcid.org/0000-0002-7340-4933

Carine Bétrisey https://orcid.org/0000-0002-6768-0667

Alida Gulfi $\quad$ https://orcid.org/0000-0001-5504-5626

Camille Brisset https://orcid.org/0000-0003-2166-7253

Nicolas Kühne https://orcid.org/0000-0001-5198-4802

Yvan Leanza $\quad$ https://orcid.org/0000-0003-0059-7049

\section{References}

American Occupational Therapy Association. (2018). Occupational therapy: Improving function while controlling costs. https://www.aota.org/About-Occupational-Therapy/Professionals.aspx

AvenirSocial. (2014). Profile of social work professionals [Profil des professionnel-le-s du travail social]. http://www.avenirsocial.ch/cm_data/AS_Berufsbild_FR_RZ_low_28.10.14.pdf

Bradley, C., Maschi, T., O’Brien, H., Morgen, K., \& Ward, K. (2012). Faithful but different: Clinical social workers speak out about career motivation and professional values. Journal of Social Work Education, 48(3), 459-477. https://doi.org/10.5175/JSWE.2012.201000043

Braun, V., \& Clarke, V. (2006). Using thematic analysis in psychology. Qualitative Research in Psychology, 3(2), 77-101. https://doi.org/10.1191/1478088706qp063oa

Byrne, N. (2015). Exposure to occupational therapy as a factor influencing recruitment to the profession. Australian Occupational Therapy Journal, 62(4), 228-237. https://doi.org/10.1111/14401630.12191

Careau, E., \& Vallée, C. (2014). Qualitative research and scientificity [Recherche qualitative et scientificité]. In S. Tétreault \& P. Guillez (Eds.), Practical guide to rehabilitation research [Guide pratique de recherche en réadaptation], (pp. 489-508). De Boeck Supérieur.

Careau, E., Vincent, C., \& Swaine, B. R. (2014). Observed interprofessional collaboration (OIPC) during interdisciplinary team meetings: Development and validation of a tool in a rehabilitation setting. Journal of Research in Interprofessional Practice and Education, 4(1), 1-19. https://doi.org/10.22230/jripe.2014v4n1a118

Carter, N., Bryant-Lukosius, D., DiCenso, A., Blythe, J., \& Neville, A. J. (2014). The use of triangulation in qualitative research. Oncology Nursing Forum, 41(5), 545-547. https://doi.org/10.1188/14.ONF.545-547

Craik, C., \& Zaccaria, J.-M. (2003). The career choice of first-year occupational therapy students: A follow-up study. British Journal of Occupational Therapy, 66(11), 531-534. https://doi.org/10.1177/030802260306601107

Creswell, J. W. (2014) Research design: Qualitative, quantitative and mixed methods approaches (4th ed.). Sage. 
Csikai, E. L., \& Rozensky, C. (1997). 'Social work idealism' and students’ perceived reasons for entering social work. Journal of Social Work Education, 33(3), 529-538.

https://doi.org/10.1080/10437797.1997.10778891

Davis, J. (2008). Occupational therapy students' metaphors for helping. American Journal of Occupational Therapy, 62, 242-250. https://doi.org/10.5014/ajot.62.2.242

Egan, G. (2018). The skilled helper: A client-centered approach (2nd ed.). Cengage.

Fleming, J., Gilbert, J., McKenna, K., \& Heath, T. (1997). First year occupational therapy students: Profile and perceptions. Australian Occupational Therapy Journal, 44(3), 107-118. https://doi.org/10.1111/j.1440-1630.1997.tb00763.x

Freund, A., Cohen, A., Blit-Cohen, E., \& Dehan, N. (2017). Professional socialization and commitment to the profession in social work students: A longitudinal study exploring the effect of attitudes, perception of the profession, teaching, training, and supervision. Journal of Social Work, 17(6), 635-658. https://doi.org/10.1177/1468017316651991

Hackett, S., Kuronen, M., Matthies, A.-L., \& Kresal, B. (2003). The motivation, professional development and identity of social work students in four European countries. European Journal of Social Work, 6(2), 163-178. https://doi.org/10.1080/1369145032000144421

Hanson, J. G., \& McCullagh, J. G. (1995). Career choice factors for BSW students: A 10-year perspective. Journal of Social Work Education, 31(1), 28-37. https://doi.org/10.1080/10437797.1995.10778836

Imbert, G. (2010). The semi-directive interview: On the border of public health and anthropology [L'entretien semi-directif: à la frontière de la santé publique et de l'anthropologie]. Recherche en Soins Infirmiers [Nursing Research], 102(3), 23-34. https://doi.org/10.3917/rsi.102.0023

International Federation of Social Workers. (2018). Global definition of social work. https://www.ifsw.org/what-is-social-work/global-definition-of-social-work/

Larson, K. E., \& Bradshaw, C. P. (2017). Cultural competence and social desirability among practitioners: A systematic review of the literature. Children and Youth Services Review, 76, 100-111. https://doi.org/10.1016/j.childyouth.2017.02.034

Maxwell, J. A. (2013) Qualitative research design. An interactive approach (3rd ed.). Sage.

McKenna, K., Scholtes, A. -A., Fleming, J., \& Gilbert, J. (2001). The journey through an undergraduate occupational therapy course: Does it change students' attitudes, perceptions and career plans? Australian Occupational Therapy Journal, 48(4), 157-169. https://doi.org/10.1046/j.14401630.2001.00248.x

Miles, M. B., Huberman, A. M., \& Saldaña, J. (2014). Qualitative data analysis (3rd ed.). Sage.

Miller, S. E. (2013). Professional socialization: A bridge between the explicit and implicit curricula. Journal of Social Work Education, 49(3), 368-386. https://doi.org/10.1080/10437797.2013.796773

Plano Clark, V. L., Anderson, N., Wertz, J. A., Zhou, Y., Schumacher, K., \& Miaskowski, C. (2015). Conceptualizing longitudinal mixed methods designs: A methodological review of health sciences research. Journal of Mixed Methods Research, 9(4), 297-319. https://doi.org/10.1177/1558689814543563

Shenton, A. K. (2004). Strategies for ensuring trustworthiness in qualitative research projects. Education for Information, 22(2), 63-75. https://doi.org/10.3233/EFI-2004-22201 
Swiss Association of Occupational Therapists and the Committee of Swiss Schools of Occupational Therapy. [Comité des Écoles Suisses d'Ergothérapie et Comité des Écoles Suisses d'Ergothérapie.]. (2005). Professional profile of occupational therapy [Profil professionnel de l'ergothérapie]. https://www.ergotherapie.ch/download.php?id=416

Taylor, R. R. (2008). The intentional relationship: Occupational therapy and use of self. F.A. Davis.

Tétreault, S., Gulfi, A., \& Kühne, N. (2016). Relationship to the Other: Exploring its evolution within social work and occupational therapy students. Grant application to the Swiss National Science Foundation, Lausanne, Switzerland.

Turpin, M. J., Rodger, S., \& Hall, A. R. (2012). Occupational therapy students' perceptions of occupational therapy. Australian Occupational Therapy Journal, 59(5), 367-374. https://doi.org/10.1111/j.1440-1630.2011.00988.x 


\section{Appendix 1: Interview guide}

\section{Perceptions of the chosen profession}

1. How did you come to choose occupational therapy / social work as educational program?

- Prior knowledge of the profession

- Knowledge of people working in this field

2. What attracted you to this profession?

3. Have you ever had any internship experiences that allowed you to work with people working in this profession or to do tasks related to it?

If so, can you tell me about it?

4. How would you describe occupational therapy / social work profession?

- Tasks, activities

- Workplaces

- Clients

- Competencies required 